\title{
REPAIR SHOP JOB SCHEDULING WITH PARALLEL OPERATORS AND MULTIPLE CONSTRAINTS USING SIMULATED ANNEALING
}

\author{
N. Shivasankaran ${ }^{\dagger}$ \\ Associate Professor, \\ Department of Mechanical Engineering, \\ K. S. R. College of Engineering, \\ Tiruchengode - 637 215, Tamil Nadu, India. \\ Email: shivasankaran.n@gmail.com \\ P. Senthil Kumar \\ Professor \& Head, \\ Department of Mechanical Engineering, \\ K. S. R. College of Engineering, \\ Tiruchengode - 637 215, Tamil Nadu, India. \\ G. Nallakumarasamy \\ Professor \& Head, \\ Department of Automobile Engineering, \\ K. S. R. College of Engineering, \\ Tiruchengode - 637 215, Tamil Nadu, India.
}

\author{
K. Venkatesh Raja \\ Assistant Professor, \\ Department of Automobile Engineering, \\ K. S. R. College of Engineering,
}

Tiruchengode - 637 215, Tamil Nadu, India.

Received 15 March 2012

Accepted 22 October 2012

\begin{abstract}
Scheduling problems are generally treated as NP - complete combinatorial optimization problems which is a multi-objective and multi constraint one. Repair shop Job sequencing and operator allocation is one such NP - complete problem. For such problems, an efficient technique is required that explores a wide range of solution space. This paper deals with Simulated Annealing Technique, a Meta - heuristic to solve the complex Car Sequencing and Operator Allocation problem in a car repair shop. The algorithm is tested with several constraint settings and the solution quality exceeds the results reported in the literature with high convergence speed and accuracy. This algorithm could be considered as quite effective while other heuristic routine fails.
\end{abstract}

Keywords: Car sequencing; Simulated Annealing Technique; Repair Shop; Optimization; Operator allocation; Cost Minimization.

\section{INTRODUCTION}

The objective of the scheduling problems is to deal with allocating resources with a single or set of objectives and constraints to perform a set of activities ${ }^{[1]}$. These scheduling problems arise in a variety of services and manufacturing organizations. Repair shop environments are one such area which is characterized by a greater degree of uncertainty than traditional job or assembly shop environments, and this introduces unique managerial complications. In an automobile repair shop, a client leaves his car to a service advisor. After a short diagnosis, the service advisor negotiates with the client about delivery time. Thereto, the car is sent inside the automobile shop for repair. At the established due date, the client should be able to pick up the car. However in practice as in most of the cases it is highly non-feasible due to improper assignment and non-optimal car sequencing.

Most of the research works in scheduling have been carried out on manufacturing organizations. Few service sector scheduling researches are reviewed subsequently in this chapter. Oualid Jouini et al. ${ }^{[2]}$ proposed online scheduling policies for reducing expected 
waiting times of calls in call centers by adjusting their routing rules with dynamic change in parameters. Robinson L. W. ${ }^{[3]}$ illustrated Monte Carlo Integration, which is a closed form of heuristics for scheduling doctor's appointments. Park Y. et al. ${ }^{[4]}$ adopted Trend Analysis for the optimal assignment of check-in counters in Airports based on the arrival pattern of customers. Hwang J. [5] conducted a study in restaurant table management to reduce the customer waiting time, decision making and time of table sit empty. Le L. et al. ${ }^{[6]}$ formulated a Dantzig Wolfe decomposition algorithm for optimum scheduling of flights which maintain competitive prices and services. A GRASP approach designed by Goodman M. D. et al. ${ }^{[7]}$ and Chang-Chun Tsai ${ }^{[8]}$ two-stage Genetic Algorithm based approach proposes optimal nurse scheduling in hospitals.

Ernst A. T. et al. ${ }^{[9]}$ presented a review on staff scheduling and rostering in job shops. Subramaniam .V et al. [10] proposed Modified Affected Operation Rescheduling (mAOR) for rescheduling the repair process when multiple disruptions are encountered during real shop floor uncertain scheduling. Corominas A. et al. ${ }^{[11]}$ allocated the tasks to the multifunctional workers in a service industry using Jonker and Volgenant routine algorithm. Alcaide D et al. ${ }^{[12]}$ uses stochastic approach to minimize make-span in open shop scheduling. Soyuer. H. [13] introduced Expert system with two dimensions (information and interface) for multiple parallel channels processing to minimize setup and completion time. Furthermore, B. Naderi et al. ${ }^{[14]}$ devised two different encoding schemes with the help of hybridization of Memetic Algorithm and Simulated Annealing to schedule open shop having parallel machines to minimize total completion time.

A simulation model had been presented by Kim S. C. et al. ${ }^{[15-17]}$ for balancing the number of beds available and deterministic arrivals in ICU after a surgical intervention in hospitals for each day. Hojati M. et al. ${ }^{[18]}$ considered a two-stage procedure for solving the employee scheduling problem in fast food restaurant services employing heterogeneous, part-time employees with limited availability. Here the employee shifts are determined using a series of small integer linear programs for each task per day and then, an integer linear programming-based heuristic is used to assign the good shifts to the employees, one employee at a time. These integer linear programs were solved using Excel's standard Solver to find a feasible solution for assigning the good shifts and scheduling time to all employees for 160 shifts per week.

Liaw C-F ${ }^{[19]}$ developed a neighborhood search algorithm using Simulated Annealing technique for open shop scheduling which minimizes make-span. Neural Network approach designed by Ahmed El-Bouri et al. ${ }^{[20]}$ minimizes make-span and flow time in job shops. Bansal N. et al. ${ }^{[21]}$ devised and tested two competitive online due date scheduling algorithms to quote the reliable due date to the customers. The complexity involved in solving these scheduling problems renders attraction for the academia and researchers in developing new optimization algorithms. The solution of these scheduling problems yields benefits of lowering cost, matching workload to available capacity, minimizing the completion time, smoothen the flow of customers and improving productivity in organizations.

There has been several works on solving quality and scheduling related problems in Automobile repair shops. Saravanan R. et al. ${ }^{[22-24]}$ identified twelve critical factors for implementing Total Quality Management (TQM) in service industries. Parameshwaran R. et al. ${ }^{[25-}$ ${ }^{28]}$ utilized the tools such as Brown Gibson Model, fuzzy Analytical Hierarchical process (AHP), Integrated fuzzy logic, Data Envelopment Analysis (DEA), Fuzzy failure mode and effect analysis (FMEA) for improving service quality in automobile repair shops . They also implemented Likert scale for measuring service quality in automobile service sectors. The level of providing services as per the promised delivery schedule has been dropped for improving reliability of service quality.

Boer R. de et al. ${ }^{[29]}$ used an iterative scheduling technique developed by $\mathrm{Li}$. R. Y. et al. ${ }^{[30]}$ to find a feasible schedule for a large maintenance shop such as dockyard in which the time to complete all maintenance activities is minimized. Bard J. F. et al. ${ }^{[31]}$ formulated a pure Integer Programming model for scheduling workers in postal services and solved using CPLEX optimization engine to minimize the labor costs. Bell J. E. et al ${ }^{[32]}$ used a two-stage maximal covering location problem (MCLP) Model developed by ReVelle C. S. et al. ${ }^{[33]}$ and Microsoft Excel with the premium solver have been used to solve for two security patrol areas that best utilize all available maintenance teams and security personnel at F. E. Warren AFB. This concept has been evolved from location set covering problem (LSCP) for locating emergency service facilities presented by Toregas C. et al. ${ }^{[34]}$. Brucker P. ${ }^{[35]}$ and Pinedo M. L. ${ }^{[36]}$ discussed the scheduling theories and algorithms for different shops using optimization and approximation approaches.

Yair M. Babad et al. ${ }^{[37]}$ considered exponential and non-exponential service distributions for service center involving appointments and developed simple operational scheduling model for them. Hassin R. et al. ${ }^{[38]}$ developed a Greedy Heuristic Greedy Rule model to schedule and optimize the long run average cost incurred for each 
machine maintenance. Yang J. ${ }^{[39]}$ discussed in his thesis about the scheduling of jobs having unique objectives in repair shops. For minimizing total tardiness, earliness and inventory holding costs, Luh P. B. et al. ${ }^{[40]}$ have developed a combinatorial model by combining Lagrangian relaxation, stochastic dynamic programming with heuristics. But it only minimizes the number of unassigned tasks. Joseph. Y. et al. ${ }^{[41]}$ developed Tabu search algorithm for solving two new heuristics i.e. shortest processing time first applied to machine with largest load (SPTL) and earliest completion time first (ECT) in scheduling the parallel resource environment. Scheduling and Local Search (SLS) method was used by Quintanilla S. et al. ${ }^{[42]}$ for establishing the fitness of the initial schedule and further Genetic Algorithm has been used to schedule the tasks and assign the resources (workers) in service centers. LIHU A. et al. ${ }^{[43]}$ presented task swap, squeaky wheel optimization, value biased stochastic sampling, bee colony optimization, reinforced learning algorithms for scheduling the repair shops. Srinivasan V. et al. ${ }^{[44]}$ developed a heuristic schedule using intelligent generate and test approach by assigning weights to different tasks in service shops.

However to the author's knowledge, optimization of a Car Sequencing and Operator Allocation (CSOA) problem using Simulated Annealing Technique (SAT) has not been addressed so far. Moreover, the quantum of work in this area seems to be negligible. In this work, the attempt has been made to solve this complex CSOA problem using SAT, which is having a high degree of difficulty.

Further sections of the paper are organized as follows. The concept, characteristics of the problem and optimization model of car repair shop scheduling is discussed in Section 2. The working mechanism of the algorithm is expounded in section 3. Section 4 describes the computational experiments followed by results and discussion and conclusion in section 5 and 6 respectively.

\section{CAR SHOP SCHEDULING:}

The car repair shop requires to schedule a set of $n$ repair jobs must be processed by $m$ operators, and each job $j_{i}$ has $k$ operations. These operations are to be performed with a set of $\mathrm{C}$ constraints. The scheduling task is to find the schedule $\mathrm{X}$ for the jobs that meets the defined measure of schedule optimization. If $n$ jobs and $m$ operators are considered in general case, there will be $(n !)^{m}$ feasible assignments as discussed by P.Mellor ${ }^{[45]}$. So if $n$ jobs have $p$ operations then, there will be $(n p !)^{m}$ feasible assignments are possible which have been proved from the results obtained in case study 1,2 and 3 .
The problem addressed in this study is daily scheduling of operators for an automobile repair shop. The main objective of this work is to assign m duties to $n$ staff, subject to set of resources and regulatory constraints. The authors presented the Simulated Annealing Technique (SAT) discussed by Nallakumarasamy G. et al. ${ }^{[46]}$ for solving this CSOA problem.

\subsection{The characteristics of the problem}

In this section, we present an Integer Linear programming model to formulate the CSOA with parallel operators in each time span of working hours.

The problem considered in this study has the following assumptions and characteristics.

(i) Operations must be executed in a consecutive time span without breaks.

(ii) The successive operation of each job depends on the completion of previous operation of the same job.

(iii) No parallel operations are to be performed in a job at a time.

(iv) Only one operation is to be executed at a time by an operator.

(v) No two jobs have the similar operations throughout its repair time.

(vi) All the Operators are to be scheduled based on their availability.

(vii) Each Operator must be given scheduled time off in a day. These day offs are not consecutive and is unique for different operators.

(viii) Each Operator has to start his work only after the arrival of the job to the repair shop and no preemption is allowed for any job.

(ix) Tasks should be completed with the available time span.

\subsection{Mathematical Programming Model of the problem}

It is worth pointing out that the model should satisfy the multiple objectives such as minimizing the total cost and make span of every operations in all jobs and multiple constraints such as operations should not be preempted for any job, workload to be balanced for all operators. The notations used to represent objective function and constraints are given below.

Indices

$\begin{array}{ll}i & \text { index of job; } 1 \leq i \leq n \\ j & \text { index of operator; } 1 \leq j \leq m \\ k & \text { index of operation; } 1 \leq k \leq \mathrm{y}_{i}\end{array}$




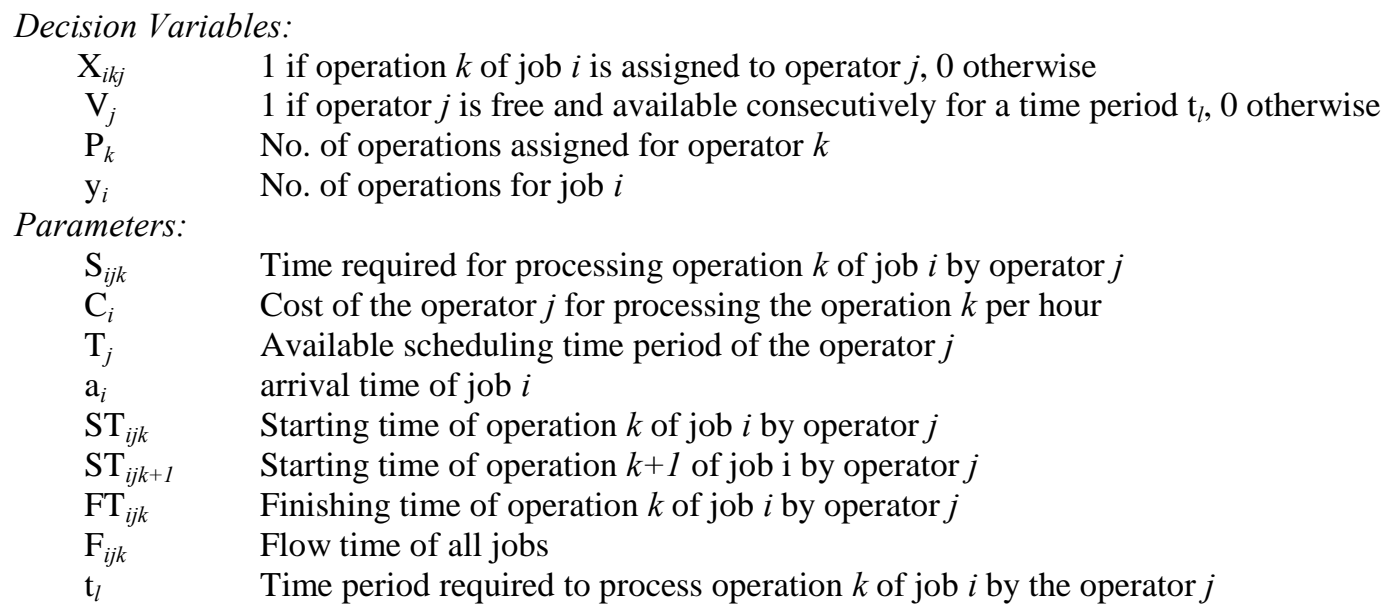

Formulation:

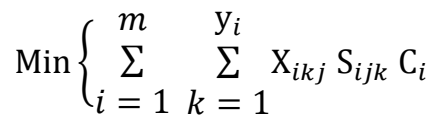

$$
\begin{aligned}
& \operatorname{Min}\left\{\sum_{i=1}^{n} \mathrm{X}_{i k j} \mathrm{~F}_{i j k}\right. \\
& \text { Subject to } \\
& \begin{array}{l}
\sum_{i=1}^{m} \sum_{k=1}^{\mathrm{y}_{i}} \mathrm{X}_{i k j} \mathrm{~S}_{i j k} \leq \mathrm{T}_{j} \quad \forall k \in i \\
\mathrm{ST}_{\mathrm{ijk}} \geq \mathrm{a}_{\mathrm{i}} \\
\mathrm{ST}_{i j k+1} \geq \mathrm{ST}_{i j k}+\mathrm{X}_{i k j} \mathrm{~S}_{i j k} \\
\quad m \quad \mathrm{y}_{i} \mathrm{y}_{i} P_{k} \mathrm{~V}_{j} \mathrm{t}_{l}=0 \\
\sum_{i=1} \mathrm{X}_{i k j} \mathrm{~S}_{i j k}-\sum_{j=1} V_{l=1} V=1 \\
\mathrm{FT}_{i j k}=\mathrm{ST}_{i j k}+\mathrm{X}_{i k j} \mathrm{~S}_{i j k} \\
\mathrm{~S}_{i j k}>0 ; \mathrm{F}_{i j k}>0 ; \mathrm{ST}_{i j k} \geq 0 ; \mathrm{T}_{j} \geq 0 ; \mathrm{t}_{l} \geq 0
\end{array}
\end{aligned}
$$

Eq. (1) is the fitness function that minimizes the total cost of servicing; Eq. (2) describes the maximum flow time among all the jobs; Constraint (3) defines the decision variable; Constraint (4) ensures that every operator is to be allotted only for their available time; Constraint (5) depicts that operation to be done only after the arrival of the job; Constraint (6) sets the dependence of previous operation on the same job; Constraint (7) represents the operation to be done consecutively without split-ups; Constraint (8) is to calculate the finish time of each job.

\section{SIMULATED ANNEALING TECHNIQUE (SAT):}

Simulated annealing (SA) is a generic probabilistic metaheuristic for the global optimization problem in locating a good approximation to the global optimum of a given function in a large search space. Annealing refers to the process when physical substances are raised to a high energy level and then gradually cooled until some solid state is reached. The goal of this process is to reach the lowest energy state. In this process, physical substances usually move from higher energy states to lower ones if the cooling process is sufficiently slow. However, there is some probability at each stage of the cooling process that a transition to a higher energy state will occur, but this probability of moving to higher energy state decreases in this process.

Simulated annealing solves the problem by allowing worse moves (lesser quality) to be taken some times. That is, it allows some uphill steps based on some acceptance criteria so that it can escape from local minima. The basic requirement in $\mathrm{SA}$ is that the temperature should decrease neither too fast which is not stable, nor too slow which will result into low efficiency of the algorithm. Accepting probability is the probability that it accepts worse solutions. Kirkpatrick S. et al. ${ }^{[47]}$ has discussed the probability of accepting a worse move is a function of both the temperature of the system and of the change in the cost function. It allows the algorithm to jump out of local minima and proceeds towards global minima due to solution space reduction technique in SA as discussed by Nallakumarasamy G. et al. ${ }^{[48]}$ which shrinks the solution space by $99.975 \%$ that greatly 
reduces the computational time and improves the solution quality from the initial solution onwards. Generally, when temperature is high, this probability is high. As the temperature becomes lower, this probability gradually decreases to 0 . And then the algorithm stops.
A generic procedure for simulated annealing as defined by Johnson et al. ${ }^{[49]}$ is given below in fig. 1 for the minimization problems and is to be modified according to the requirement.

Begin

Fig. 01- Pseudo Code for SA Algorithm

Obtain an initial solution, $\mathrm{S}$.

Obtain an initial temperature, $\mathrm{T}>0$.

While (termination condition not met) do

Pick a random neighbour S' of S.

Let $\Delta=\operatorname{cost}\left(\mathrm{S}^{\prime}\right)-\operatorname{cost}(\mathrm{S})$

If $\Delta \leq 0$ (downhill move),

Then set $\mathrm{S}=\mathrm{S}$ '.

else (if $\Delta>0$ (uphill move)),

Set $\mathrm{S}=\mathrm{S}^{\prime}$ with probability $\exp (-\Delta / \mathrm{T})$.

Perform the following loop $\mathrm{L}$ times.

Return S.

Set $\mathrm{T}=\mathrm{rT}$ (reduce temperature)

End.

\section{COMPUTATIONAL EXPERIMENTS :}

In this paper we considered the problem illustrated by Srinivasan V. et al. ${ }^{[44]}$, while repair works for all cars may be distinct, each comprises of nonidentical service time and cost characteristics. The Operators are assumed to be paid in an hourly basis and there is no previous days pending works to be done.

The parameters such as car arrival time, tasks to be executed in each car are given in Table 01. The operator costs and repair time consumed by each operator is presented in Table 02. The Table 03 shows the availability time span of the operator in repair shop. The case study-1 discusses the operations to be executed with operator availability, make-span minimization, workload balancing constraints. The case study-2 deals with operations executed in all-time operator availability and case study-3 deals with unbalancing workload and minimizing the total cost.

Table 01 - Car Arrival and Repair Data

\begin{tabular}{|c|c|c|c|c|c|c|c|c|}
\hline \multirow{2}{*}{ Car No. } & \multirow{2}{*}{$\begin{array}{c}\text { Arrival } \\
\text { Time }\end{array}$} & \multicolumn{9}{|c|}{ Type of Tasks } \\
\cline { 3 - 9 } & Brakes & Gasket & Fender & Muffler & Transmission & Oil Change & Tune up \\
\hline 1 & 0 & - & - & - & - & 1 & - & 2 \\
\hline 2 & 0 & 3 & 4 & - & - & 5 & - & - \\
\hline 3 & 4 & 6 & - & 7 & - & - & 8 & - \\
\hline 4 & 5 & 9 & 10 & - & - & - & - & - \\
\hline 5 & 5 & - & - & - & 11 & 12 & - & - \\
\hline
\end{tabular}

Table 02 - Operator Cost \& Repair Durations

\begin{tabular}{|c|c|c|c|c|c|c|c|c|}
\hline \multicolumn{2}{|c|}{ Operator } & \multicolumn{7}{c|}{ Task Durations (Hrs.) } \\
\hline & Cost / Hr. & Brakes & Gasket & Fender & Muffler & Transmission & Oil Change & Tune up \\
\hline Al & 4 & 1 & 2 & 2 & 1 & 2 & 1 & 3 \\
\hline Bert & 1 & 3 & 3 & 4 & 2 & 5 & 2 & 5 \\
\hline Chip & 2 & 3 & 3 & 4 & 2 & 3 & 2 & 3 \\
\hline Joe & 3 & 1 & 2 & 2 & 1 & 3 & 1 & 3 \\
\hline Charles & 2 & 3 & 3 & 2 & 1 & 3 & 1 & 3 \\
\hline
\end{tabular}

Table 03 - Operator Availability

Table 04 - Operation Precedence Constraints

\begin{tabular}{|c|c|}
\hline Operator & Available Time span (Hrs.) \\
\hline Al & $(4-8),(9-12)$ \\
\hline Bert & $(1-9),(11-16)$ \\
\hline Chip & $(2-7),(9-16)$ \\
\hline Joe & $(2-5),(7-12)$ \\
\hline Charles & $(2-8),(10-14)$ \\
\hline
\end{tabular}

\begin{tabular}{|c|l|}
\hline Car No. & \multicolumn{1}{|c|}{ Precedence Order } \\
\hline Car 1 & Fix Transmission, Tune Up \\
\hline Car 2 & Fix Brakes, Change Gasket, Fix Transmission \\
\hline Car 3 & Fix Brakes, Fix Fender and Oil change \\
\hline Car 4 & Fix Brakes, Change Gasket \\
\hline Car 5 & Change Muffler, Fix Transmission \\
\hline
\end{tabular}




\section{Results and Discussion}

The SA Algorithm is coded in Turbo $\mathrm{C}++$ on Pentium IV desktop computer with a $2.4 \mathrm{GHz}$ processor with an initial temperature parameter setting of 1000 , reduced by a cooling factor of 0.9 with a termination temperature of 50. These parameters are set as presented by Parthasarathy $\mathrm{S}$. et al. ${ }^{[50]}$ for allowing the algorithm for 30 temperature ranges. The car sequencing and operator allocation (CSOA) algorithm developed is able to give optimal solutions for varieties of operation requirements, operator availability and allocations. In algorithm, there is no asserts and retracts used, although cuts were used purely for efficiency reasons.

\subsection{Case Study - 01:}

The problem with an optimal schedule is presented by comparing case study results. The best sequence and operator allocation is obtained using multi objective, multi constrained integer programming model developed using SAT. Here, the objective function considered is Balancing workload, minimizing Job flow time and Total cost. The constraints are availability of the Operator, Job arrival time and job precedence order constraint. The precedence order is tabulated in table 4 respectively. This makes the system a NP-Complete problem. The possible sequences are tabulated in Table -05 . The best possible allocation of operation which satisfies all the above criteria is presented in Table -06 . The iterations converge as shown in figure 02 .

Table 05 Possible Schedules for case study - 1

\begin{tabular}{|l|c|c|c|c|}
\hline $\begin{array}{c}\text { Iteration } \\
\text { No. }\end{array}$ & Operator Allocation & $\begin{array}{c}\text { Objective } \\
\text { Function }\end{array}$ & $\begin{array}{c}\text { Flow time for each job } \\
\text { (Hrs.) }\end{array}$ & $\begin{array}{c}\text { Max. Flow } \\
\text { Time (Hrs.) }\end{array}$ \\
\hline 1. & $3-2-1-1-1-4-5-5-4-4-5-3$ & 57 & $16-11-4-5-7$ & 16 \\
\hline 2. & $3-5-1-2-1-1-4-5-4-4-2-3$ & 56 & $8-11-8-7-11$ & 11 \\
\hline 3. & $3-5-4-2-1-4-4-5-4-1-2-3$ & 56 & $8-7-6-7-7$ & 8 \\
\hline 4. & $5-3-4-2-1-4-1-5-1-2-4-3$ & 55 & $12-8-8-4-10$ & 12 \\
\hline 5. & $3-3-4-4-1-1-5-2-1-2-4-5$ & 55 & $12-7-5-9-6$ & 12 \\
\hline 6. & $5-3-1-2-1-1-5-2-4-4-4-3$ & 55 & $12-11-12-5-9$ & 12 \\
\hline 7. & $5-3-1-4-1-1-5-2-4-2-4-3$ & 55 & $12-11-9-11-10$ & 12 \\
\hline 8. & $5-3-4-4-1-4-5-1-1-2-2-3$ & 55 & $12-7-7-9-10$ & 12 \\
\hline 9. & $5-3-1-2-1-4-1-5-4-2-4-3$ & 55 & $12-11-10-6-10$ & 12 \\
\hline 10. & $5-3-1-2-1-4-5-2-1-4-4-3$ & 55 & $12-11-9-4-10$ & 12 \\
\hline 11. & $3-5-4-2-1-4-5-2-4-1-4-3$ & $55 *$ & $8-8-9-6-7$ & $9 *$ \\
\hline 12. & $3-5-1-2-1-4-5-1-4-4-2-3$ & 55 & $8-11-8-5-11$ & 11 \\
\hline 13. & $5-3-4-1-1-4-5-4-4-2-2-3$ & 55 & $12-8-4-9-10$ & 12 \\
\hline 14. & $5-3-4-4-1-1-5-2-1-2-4-3$ & 55 & $12-7-5-9-10$ & 12 \\
\hline 15. & $3-5-1-2-1-4-5-4-1-4-2-3$ & 55 & $12-11-4-5-11$ & 12 \\
\hline 16. & $5-3-4-4-1-1-5-1-4-2-2-3$ & 55 & $12-7-4-9-10$ & 12 \\
\hline 17. & $5-3-4-1-1-4-5-2-4-2-4-3$ & 55 & $12-8-5-9-10$ & 12 \\
\hline 18. & $3-3-4-1-1-4-5-4-4-2-2-5$ & 55 & $12-8-4-9-5$ & 12 \\
\hline 19. & $3-5-4-4-1-1-5-1-4-2-2-3$ & $55 *$ & $8-7-7-9-7$ & $9 *$ \\
\hline 20. & $5-3-4-2-1-1-5-1-4-4-2-3$ & 55 & $12-8-6-5-10$ & 12 \\
\hline 21. & $3-5-4-2-1-4-1-5-4-2-1-3$ & 55 & $8-8-8-9-7$ & 9 \\
\hline
\end{tabular}

Table 06 Optimal Schedule for case study - 1 (Sample Result)

\begin{tabular}{|c|c|c|c|c|c|}
\hline Car & Tasks & $\begin{array}{l}\text { Starting time } \\
\text { (Hrs.) }\end{array}$ & $\begin{array}{l}\text { Finishing time } \\
\text { (Hrs.) }\end{array}$ & Operator & $\begin{array}{l}\text { Job Flow time } \\
\text { (Hrs.) }\end{array}$ \\
\hline \multirow{2}{*}{ Car 1} & Fix Transmission & 2 & 5 & Chip & \multirow{2}{*}{8} \\
\hline & Tune Up & 5 & 8 & Charles & \\
\hline \multirow{3}{*}{ Car 2} & Fix brakes & 2 & 3 & Joe & \multirow{3}{*}{7} \\
\hline & Change Gasket & 3 & 5 & Joe & \\
\hline & Fix Transmission & 5 & 7 & $\mathrm{Al}$ & \\
\hline \multirow{3}{*}{ Car 3} & Fix brakes & 4 & 5 & $\mathrm{Al}$ & \multirow{3}{*}{7} \\
\hline & Fix fender & 8 & 10 & Charles & \\
\hline & Oil change & 10 & 11 & $\mathrm{Al}$ & \\
\hline \multirow{2}{*}{ Car 4} & Fix brakes & 7 & 8 & Joe & \multirow{2}{*}{9} \\
\hline & Change Gasket & 11 & 14 & Bert & \\
\hline
\end{tabular}




\begin{tabular}{|l|l|c|c|c|c|}
\hline \multirow{2}{*}{ Car 5 } & Change Muffler & 5 & 7 & Bert & \multirow{2}{*}{7} \\
\cline { 2 - 5 } & Fix Transmission & 9 & 12 & Chip & \\
\hline
\end{tabular}

The optimal cost and feasible assignment was found to be reduced by 4 units which is best than the allocation done by Srinivasan. V. et al. ${ }^{[4]}$. Moreover, it has been proved that the multiple feasible solutions are possible as stated by P. Mellor [45]. The number of iterations for convergence is very less and therefore the computation time is reduced drastically. Normally, in this competitive environment, the main objective of every repair shop is to provide a quality service with minimum make span at low cost. So, this case study resulted in minimizing Total cost and make-span of every job with multiple constraints. The case study results have been compared in Table 07 .

Table 07 Results of Case Study - 1

\begin{tabular}{ccc}
\hline & Srinivasan V. et al. [44] & Proposed SA Technique \\
\hline Total cost & 59 & 55 \\
\hline $\begin{array}{c}\text { No. of Feasible Assignments } \\
\text { Maximum Flow time of Jobs in optimal } \\
\text { assignments }\end{array}$ & 1 & 18 \\
\hline $\begin{array}{c}\text { Maximum Operator Load at optimal } \\
\text { assignments }\end{array}$ & 12 & 9 \\
\hline
\end{tabular}

Fig. 02 - Convergence Graph

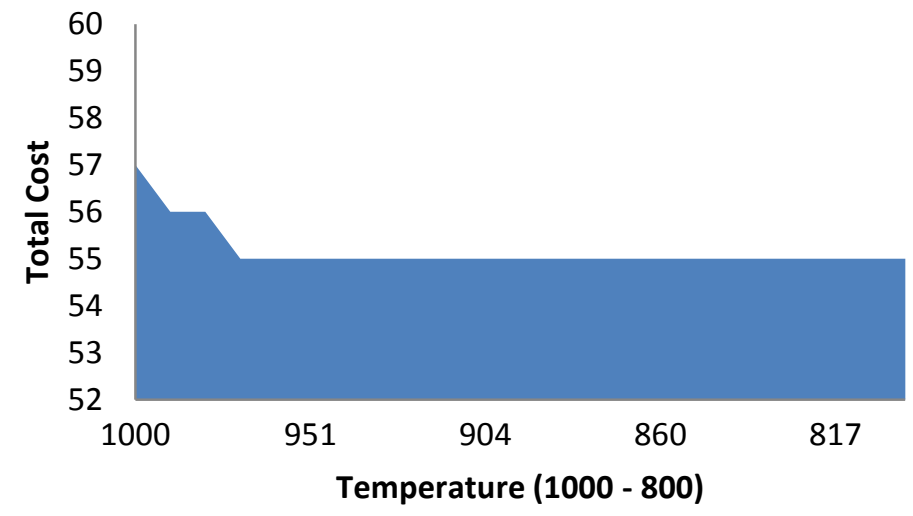

5.2 Case Study - 02:

Here, the objective function considered is Total cost and the constraints are balancing of workload, Job arrival time. The operators are assumed to be available for $(0-$
16) hours. Then the possible sequences are tabulated in Table -08 . The best results which satisfy all the above criteria are presented in Table -09 .

Table 08 Possible Schedules for case study - 2

\begin{tabular}{|c|c|c|c|c|}
\hline $\begin{array}{c}\text { Iteration } \\
\text { No. }\end{array}$ & Operator Allocation & $\begin{array}{c}\text { Objective } \\
\text { Function }\end{array}$ & $\begin{array}{c}\text { Flow time for } \\
\text { each job (Hrs.) }\end{array}$ & $\begin{array}{c}\text { Max. Flow } \\
\text { Time (Hrs.) }\end{array}$ \\
\hline 1. & $3-2-1-1-1-4-5-5-4-4-5-3$ & 57 & $8-5-5-3-3$ & 8 \\
\hline 2. & $5-3-1-2-1-4-4-5-1-2-4-1$ & 56 & $6-6-4-5-5$ & 6 \\
\hline 3. & $1-3-2-4-1-4-5-5-4-2-5-1$ & 56 & $5-7-5-5-4$ & 7 \\
\hline 4. & $1-3-1-2-1-1-4-5-4-2-4-5$ & 56 & $5-8-3-5-6$ & 8 \\
\hline 5. & $3-5-1-2-1-4-4-5-4-2-1-1$ & 56 & $6-6-4-6-4$ & 6 \\
\hline 6. & $1-3-4-2-5-4-1-5-4-2-4-1$ & 56 & $5-7-4-4-4$ & 7 \\
\hline 7. & $1-3-2-2-1-4-5-5-4-4-5-1$ & 56 & $5-8-4-3-6$ & 8 \\
\hline $\mathbf{8 .}$ & $3-5-1-2-1-4-4-5-4-2-5-1$ & $54 *$ & $6-6-4-6-4$ & $6 *$ \\
\hline 9. & $1-3-4-2-5-4-5-4-1-2-4-1$ & 54 & $5-7-6-4-3$ & 7 \\
\hline
\end{tabular}


Table 08 ( Continued )

\begin{tabular}{|l|c|c|c|c|}
\hline 10. & $1-5-1-2-3-4-4-5-4-2-5-1$ & 54 & $5-9-4-6-3$ & 9 \\
\hline 11. & $1-3-4-2-1-4-4-5-1-2-5-5$ & $54^{*}$ & $5-6-5-5-4$ & $6^{*}$ \\
\hline 12. & $5-3-1-2-1-4-4-5-4-2-5-1$ & $54^{*}$ & $6-6-4-6-3$ & $6^{*}$ \\
\hline 13. & $1-3-4-2-1-4-5-4-1-2-4-5$ & $54^{*}$ & $5-6-6-5-5$ & $6^{*}$ \\
\hline 14. & $1-5-4-2-1-1-5-4-4-2-4-3$ & $54^{*}$ & $5-6-6-4-5$ & $6^{*}$ \\
\hline 15. & $1-5-4-2-3-1-4-5-4-2-5-1$ & 54 & $5-7-4-6-3$ & 7 \\
\hline 16. & $1-5-1-2-1-4-4-5-4-2-5-3$ & 54 & $5-8-4-7-4$ & 8 \\
\hline 17. & $3-5-4-2-1-4-5-4-1-2-4-1$ & $54^{*}$ & $6-6-5-5-4$ & $6^{*}$ \\
\hline 18. & $1-3-1-2-5-4-5-4-4-2-4-1$ & 54 & $5-9-8-4-4$ & 9 \\
\hline 19. & $5-3-4-2-1-4-5-1-4-2-4-1$ & $54^{*}$ & $6-6-5-4-6$ & $6^{*}$ \\
\hline 20. & $1-3-4-2-1-1-4-5-4-2-5-5$ & $54^{*}$ & $5-6-6-4-4$ & $6^{*}$ \\
\hline 21. & $1-5-4-2-3-4-4-5-1-2-5-1$ & 54 & $5-7-4-4-3$ & 7 \\
\hline 22. & $3-5-1-2-1-4-5-4-4-2-4-1$ & $54^{*}$ & $6-6-5-5-4$ & $6^{*}$ \\
\hline
\end{tabular}

Table 09 Results of Case Study - 2

\begin{tabular}{ccc}
\hline & Srinivasan V. et al. [44] & Proposed SA Technique \\
\hline Total cost & 59 & 54 \\
\hline $\begin{array}{c}\text { No. of Feasible Assignments } \\
\text { No. of Optimal Assignments }\end{array}$ & 2 & 15 \\
\hline $\begin{array}{c}\text { Maximum Flow time of Jobs in optimal } \\
\text { assignments }\end{array}$ & 2 & 9 \\
\hline $\begin{array}{c}\text { Average Operator Load at Optimal } \\
\text { assignments }\end{array}$ & 9 & 6 \\
\hline $\begin{array}{c}\text { Maximum Operator Load at optimal } \\
\text { assignments }\end{array}$ & 4.8 & 4.6 \\
\hline
\end{tabular}

\subsection{Case Study - 03:}

Here, the objective function considered is only Total cost and the constraint is Job arrival time. The operators are assumed to be available for $(0-16)$ hours and eliminating work load balancing constraint. Then the possible sequences are tabulated in Table -10 . The best possible allocation of operation which satisfies all the above criteria is presented in Table -11 .

Table 10 Possible Schedules for case study -3

\begin{tabular}{|c|c|c|c|c|}
\hline $\begin{array}{l}\text { Iteration } \\
\text { No. }\end{array}$ & Operator Allocation & $\begin{array}{l}\text { Objective } \\
\text { Function }\end{array}$ & $\begin{array}{c}\text { Flow time for each } \\
\text { job (Hrs.) }\end{array}$ & $\begin{array}{l}\text { Max. job Flow } \\
\text { Time (Hrs.) }\end{array}$ \\
\hline 1. & $1-5-1-2-4-4-1-5-4-2-2-3$ & 57 & $5-9-4-4-9$ & 9 \\
\hline 2. & $5-5-2-2-3-1-5-4-5-2-2-5$ & 52 & $6-9-5-9-9$ & 9 \\
\hline 3. & $2-3-4-4-5-4-5-2-2-1-2-1$ & 50 & $8-6-7-6-11$ & 11 \\
\hline 4. & $1-3-4-2-5-2-2-2-4-2-4-5$ & 50 & $5-7-8-10-5$ & 10 \\
\hline 5. & $2-5-1-3-3-1-5-5-4-2-2-2$ & 50 & $8-7-7-4-11$ & 11 \\
\hline 6. & $3-5-1-2-3-1-5-5-4-2-2-3$ & 49 & $6-7-5-4-9$ & 9 \\
\hline 7. & $5-3-4-2-5-2-2-2-1-2-5-5$ & 48 & $6-7-9-11-6$ & 11 \\
\hline 8. & $2-5-4-2-3-2-5-4-4-2-4-5$ & 48 & $8-11-10-9-6$ & 11 \\
\hline 9. & $3-2-4-2-2-4-5-5-4-5-5-3$ & 48 & $8-16-4-6-10$ & 16 \\
\hline 10. & $5-5-4-2-2-1-2-5-1-2-5-5$ & 47 & $6-9-10-11-6$ & 11 \\
\hline 11. & $3-3-4-2-2-2-5-5-1-2-5-5$ & 46 & $6-9-11-10-4$ & 11 \\
\hline 12. & $2-5-2-2-5-4-5-5-4-2-2-3$ & 45 & $8-14-7-11-11$ & 14 \\
\hline 13. & $2-3-4-2-2-4-5-5-4-2-5-5$ & 45 & $8-13-4-11-7$ & 13 \\
\hline 14. & $2-3-4-2-3-4-5-5-4-2-5-2$ & $45^{*}$ & $8-11-4-6-11$ & $11^{*}$ \\
\hline
\end{tabular}




\begin{tabular}{|l|l|l|l|l|}
\hline 15. & $2-5-4-2-2-4-5-5-4-2-5-3$ & 45 & $8-13-7-11-10$ & 13 \\
\hline 16. & $2-5-4-2-3-4-5-5-4-2-5-2$ & 45 & $8-11-8-6-11$ & 11 \\
\hline
\end{tabular}

Table 11 Results of Case Study - 3

Srinivasan V. et al. [44] Proposed SA Technique

\begin{tabular}{|c|c|c|}
\hline Total cost & 59 & 45 \\
\hline No. of Feasible Assignments & 2 & 5 \\
\hline $\begin{array}{c}\text { Maximum Flow time of Jobs in optimal } \\
\text { assignments }\end{array}$ & 9 & 11 \\
\hline $\begin{array}{c}\text { Average Operator Load at optimal } \\
\text { assignments }\end{array}$ & 6 & 5.8 \\
\hline $\begin{array}{c}\text { Maximum Operator Load at optimal } \\
\text { assignments }\end{array}$ & 10 & 16 \\
\hline
\end{tabular}

Fig. 03 - Computational Time for reaching Optimal Solution

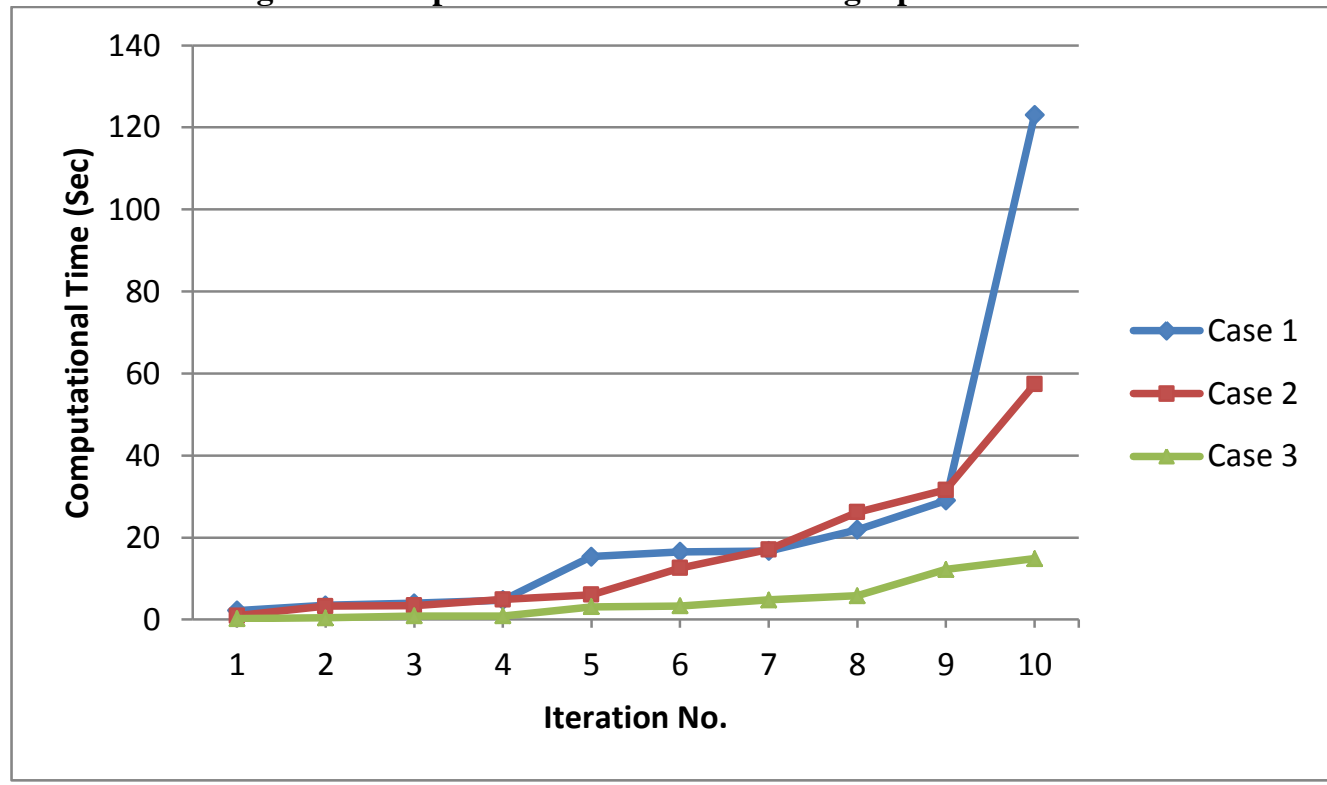

\section{Conclusion:}

In this paper, we propose SA Algorithm, a metaheuristic for solving CSOA problem in car repair shops. The application of a SAT was investigated in this work to optimize the value of total cost. The proposed methodology demonstrated a high rate of success, being able to solve problems for which other heuristic optimization routines fail. In a Scheduling system, an efficient heuristic search is required to explore the large solution space of valid resource allocation under various interacting constraints. It seems that the proposed algorithm can be treated as quite effective as in most

\section{References}

1. K.R. Baker, Introduction to Sequence and Scheduling, (Wiley, New York, 1974).

2. O. Jouini et al., Online scheduling policies for multiclass call centers with impatient customers, European Journal of Operation Research, 207 (2010) 258 - 268. cases it finds a solution which represents a good approximation to the optimal one and fast enough as shown in fig. 03 (the number of iterations and running time of the algorithm are reasonable). The result shows that the algorithm is effective in solving the NPComplete problems like resource allocation and scheduling. The proposed algorithm can be hybridized with other heuristic techniques and its robustness could be derived for possibility of achieving more optimized results and better computational time in future. 
Transportation Planning and Technology, 26 (5) (2003) 397 $-416$.

5. J. Hwang, Restaurant Table Management to Reduce Customer Waiting Times, Journal of Food Service Business Research, 11 (4) (2008) $334-351$.

6. L. Le et al., Optimum Airport Capacity Utilization under Congestion Management: A Case Study of New York LaGuardia Airport, Transportation Planning and Technology, 31 (1) (2008) 93 - 112.

7. M. D. Goodman et al., A grasp-knapsack hybrid for a nursescheduling problem, Journal of Heuristics, 15 (2009) 351 379.

8. C-C. Tsai, S.H.A. Li, A two-stage modeling with genetic algorithms for the nurse scheduling problem, Expert System with Applications, 36 (2009) 9506 - 9512.

9. A.T. Ernst et al., Staff scheduling and rostering: A review of applications, methods and models, European Journal of Operation Research 153 (2004) 3 - 27.

10. V. Subramaniam et al., Reactive repair tool for job shop schedules, International Journal of Production Research, 43 (1) (2005) $1-23$.

11. A. Corominas et al., Rotational allocation of tasks to multifunctional workers in a service industry, International Journal of Production Economics, 103 (2006) 3-9.

12. D. Alcaide, A. Rodriguez-Gonzalez, J. Sicilia, A heuristic approach to minimize expected make span in open shops subject to stochastic processing times and failures, International Journal of Flexible Manufacturing Systems, 17 (2006) $201-226$.

13. H. Soyuer, M. Kocamaz, Scheduling jobs through multiple parallel channels using an expert system, Production Planning \& Control, 18 (1) (2007) 35 - 43.

14. B. Naderi et al., Scheduling open shops with parallel machines to minimize total completion time, Journal of Computation and Applied Mathematics 235 (5) (2011) 1275 $-1287$.

15. S-C. Kim, I. Horowitz, Analysis of capacity management of the intensive care unit in a Hospital, European Journal of Operational Research, 115 (1999) $36-46$.

16. S-C. Kim, I. Horowitz, Flexible bed allocation and performance in the intensive care unit, Journal of Operations Management, 18 (2000) 427 - 443.

17. S-C. Kim, I. Horowitz, Scheduling hospital services: the efficacy of elective-surgery quotas, Omega, 30 (2002) 335 346.

18. M. Hojati, A. S. Patil, An integer linear programming-based heuristic for scheduling heterogeneous, part-time service employees, European Journal of Operational Research 209 (2011) $37-50$.

19. C-F. Liaw, Applying simulated annealing to the open shop scheduling problem, IIE Transactions, 31(1999) $457-465$.
20. A. El-Bouri, P. Shah, A neural network for dispatching rule selection in a job shop, International Journal of Advanced Manufacturing Technology, 31 (3) (4) (2006): 342 - 349.

21. N. Bansal, et al., Competitive Algorithms for Due Date Scheduling, Algorithmica, 59 (4) (2011) 569 - 582.

22. R. Saravanan, K. S. P. Rao, Development and validation of an instrument for measuring Total Quality Service, Total Quality Management \& Business Excellence, 17 (6) (2006) $733-749$.

23. R. Saravanan, K. S. P. Rao, Measurement of Service Quality from the Customer's Perspective - An Empirical Study, Total Quality Management \& Business Excellence, 18 (4) (2007) 435 - 449.

24. R. Saravanan, K. S. P. Rao, Service Quality from customer's perspective: an empirical investigation, Quality Management Journal, 14 (3) (2007) 15 - 24.

25. R. Parameshwaran, P.S.S. Srinivasan, An integrated closedloop model for service performance management, International Journal of Services and Operations Management, 4 (1) (2008) 34 - 55.

26. R. Parameshwaran et al., Modified closed loop model for service performance management, International Journal of Quality and Reliability Management: (2009) 795 - 816.

27. R. Parameshwaran et al., Integrating fuzzy analytical hierarchy process and data envelopment analysis for performance management in automobile repair shops, European Journal of Industrial Engineering, 3 (4) (2009) $450-467$.

28. R. Parameshwaran et al., An integrated approach for performance enhancement in automobile repair shops, International Journal of Business Excellence, 3 (1) (2010) 77 - 104.

29. R. D. Boer, J.M.J. Schutten, W. H. M. Zijm, A Decision Support System for Ship Maintenance Capacity Planning, Annals of the CIRP, 46 (1997) $391-396$.

30. R. Y. Li, J. Willis, An iterative scheduling technique for resource-constrained project scheduling, European Journal of Operational Research, 56 (1992) 370-379.

31. J. F. Bard, C. Binici, A. H. deSilva, Staff scheduling at the United States Postal Service, Computers \& Operations Research, 30 (5) (2003) $745-771$.

32. D. L. Overholts II, J. E. Bell, M. A. Arostegui, A location analysis approach for military maintenance scheduling with geographically dispersed service areas, Omega, 37 (2009) $838-852$.

33. R. L. Church, C. S. ReVelle, The maximal covering location problem. Papers of the Regional Science Association, 32 (1974) $101-118$.

34. C. Toregas, R. Swain, C. S. ReVelle, The location of emergency service facilities, Operations Research, 19 (1972) $1363-1373$. 
35. P. Brucker, Scheduling Algorithms, (Springer-Verlag, Berlin-Heidelberg, 1995).

36. M. L. Pinedo, Scheduling Theory algorithms and applications, (Springer - Business \& Economics, New York, 2008).

37. Yair M. Babad et al., An appointment-based service center with guaranteed service, European Journal of Operational Research, 89 (1996) 246 - 258.

38. R. Hassin, C. A. Glass, S. Anily, The scheduling of maintenance service, Discrete Applied Mathematics, 82 (1998) $27-42$.

39. J. Yang, Scheduling with batch objectives, $P h D$ Thesis, Industrial and systems engineering graduate program, (The Ohio state University, Columbus, Ohio, 1998).

40. P. B. Luh et al., A Lagrangian Relaxation Based Approach to Schedule Asset Overhaul and Repair Services, IEEE Transactions on Automation Science and Engineering, 2 (2) (2005) $145-157$.

41. Y. Joseph et al., Order scheduling in an environment with dedicated resources in parallel, Journal of Scheduling, 8 (2005) 355 - 386.

42. V. Valls, A. Perez, S. Quintanilla, Skilled workforce scheduling in Service Centres, European Journal of Operational Research, 193 (2009) 791 - 804.

43. A. LIHU, S. Holban, Top five promising algorithms in scheduling, International symposium on Applied
Computational Intelligence and Informatics, IEEE, Timisoara, Romania (2009) 397 - 404.

44. S. Venkatesh, W. Fabens, A heuristic-Based car-shop scheduling application, International Conference on tools in AI, IEEE, Arlington, VA (1992) 128 - 135.

45. P. Mellor, A review of job shop scheduling, Operation Research Quarterly, 17 (2) (1966) 161 - 171.

46. G. Nallakumarasamy et al., Optimization of operation sequencing in CAPP using simulated annealing technique (SAT), International Journal of Advanced Manufacturing Technology, 54 (5) (8) (2011) 721-728.

47. S. Kirkpatrick et al., Optimization by Simulated Annealing, Science, 220 (4598) (1983) 671-680.

48. G. Nallakumarasamy et al., Optimization of operation sequencing in CAPP using superhybrid genetic algorithmssimulated annealing technique, ISRN Mechanical Engineering, Article ID 897498 (2011) 1 - 7.

49. D. S. Johnson et al., Optimisation by simulated annealing: an experimental valuation, Part I, Graph partitioning, Operations Research, 37 (1989) 865 - 891.

50. S. Parthasarathy, C. Rajendran, A simulated annealing heuristic for scheduling to minimize mean weighted tardiness in a flowshop with sequence-dependent setup times of jobs-a case study, Production Planning \& Control, 8 (5) (1997) $475-483$. 